\title{
Enzymes of Entomopathogenic Fungi, Advances and Insights
}

\author{
Lluvia de Carolina Sánchez-Pérez ${ }^{1}$, Juan Esteban Barranco-Florido ${ }^{*}$, \\ Silvia Rodríguez-Navarro², José Francisco Cervantes-Mayagoitia², \\ Miguel Ángel Ramos-López ${ }^{3}$ \\ ${ }^{1}$ Departamento de Sistemas Biológicos, Universidad Autónoma Metropolitana, México City, México \\ ${ }^{2}$ Departamento de Producción Agrícola y Animal, Universidad Autónoma Metropolitana, México City, \\ México \\ ${ }^{3}$ Facultad de Química, Universidad Autónoma de Querétaro, Querétaro, México \\ Email: "barranco@correo.xoc.uam.mx
}

Received 27 February 2014; revised 31 March 2014; accepted 8 April 2014

Copyright (C) 2014 by authors and Scientific Research Publishing Inc.

This work is licensed under the Creative Commons Attribution International License (CC BY).

http://creativecommons.org/licenses/by/4.0/

(c) (i) Open Access

\section{Abstract}

Entomopathogenic fungi (EF) are recognized biological control agents of insects. Basically, the entomopathogenic fungi pathogen activity depends on the ability of its enzymatic equipment, consisting of lipases, proteases and chitinases, which are in charge of breaking down the insect's integument. Lipases are the first enzymes synthesized by the entomopathogenic fungi. Recently, a cytochrome P450 subfamily, referred as CYP52XI and MrCYP52 has been identified in Beauveria bassiana and Metarhizium robertsii, respectively. These break down long-chain alkenes and fatty acids to become initial nutrients. Subsequently, subtilisin type $(\operatorname{Pr} 1)$ proteases sintetize; these enzymes are considered as virulence indicators and they are regulated by a signal transduction mechanism activated by the protein kinase A (PKA) mediated by AMPc. Through the employment of genetic engineering, it has been possible to increase virulence producing Pr1 recombinants with Androctonus australis neurotoxins or with chitinases, reducing the insect's time of death. In the course of time, the Pr1 protease gene has presented evolutionary adaptations by gene duplication or horizontal transfer infecting different orders of insects. In the same way, the entomopathogenic fungi chitinases have presented a functional diversification. Currently, these have been phylogenetically classified into three subgroups, in accordance to the catalytic site domain and the chitin binding domain. The chitinolytic activity has increased through a directed evolution processes and genetic recombination with Bombyx mori chitinase. Recently, enzymes have been employed as control agents for insects and phytopathogenic fungi (disease originator) opening new potentialities in order to improve the entomopathogenic fungi use. Solid state fermentation is a bioprocess that would produce at great scale enzymes and some other metabolites in grade of increasing the entomopathogenic fungi virulence, in the control of insects and potentially in some

*Corresponding author.

How to cite this paper: de Carolina Sánchez-Pérez, L., Barranco-Florido, J.E., Rodríguez-Navarro, S., Cervantes-Mayagoitia, J.F. and Ramos-López, M.Á. (2014) Enzymes of Entomopathogenic Fungi, Advances and Insights. Advances in Enzyme Research, 2, 65-76. http://dx.doi.org/10.4236/aer.2014.22007 


\section{diseases affecting plants.}

\section{Keywords}

Lipases, Proteases, Chitinases, Host, Evolution, Biocontrol Agent

\section{Introduction}

Entomopathogenic fungi (EF) have an important position in the biological control of insect pests, due to the fact that they are responsible of causing diseases and the death of the insects [1]. Globally, the most commonly used genders are Metarhizum anisopliae (Metsch.) Sorokin (33.9\%), Beauveria bassiana (Balsam) Vullemin (33.9\%), Isaria fumosorosea (before Paecilomyces fumosoroseus) [(Wize) Brown and Smith] (5.8\%) and Beauveria brongniartii (Sacc.) Petch (4.1\%) [2]. Entomopathogenic fungi infect the insect through the cuticle. On account of this, there is no need to be ingested as they act as contact insecticides [3]. The development of the infection is divided into three stages: 1) Conidia adhesion and germination in the epicuticle of the insect [4]; germination is activated by carbohydrates present in the cuticle. Entomopathogenic fungi develop an appressorium with the purpose of beginning the penetration stage through the germ tube formation [5]. 2) The cuticle penetration is the result of combined action of mechanical force and the enzymatic action of those enzymes secreted by the fungus. Such enzymes include proteases, chitinases, lipases and lipoxygenases which break down the cuticle, offering nutrients to the fungus [1] [6] [7]. 3) Insect's propagation and death; when the fungus reaches the hemocoel, it presents a cellular hyphae differentiation to yeast-like blastospores to evade the insect immune system [8]. Entomopathogenic fungi synthesize different metabolites and depsipeptides which act as toxins, playing an important role in the infective process and provoking a series of symptoms in the insect. Among others: convulsions, lack of coordination, behavior alteration, stopping eating and paralysis. Toxicity in the secondary metabolites has been proved over the insect cellular lines, opening the possibility of developing new bioinsecticides. This can be achieved in these molecules by using molecular biology and biotechnology tools for the pest control [9]. Death results by a severe damage in the tissues, toxicosis, cell dehydration and loss of nutrient intake [10], finally the hyphae emerges from the insect body, sporulates and starts a new infection cycle. Besides, the enzymatic action offers nutrients to the fungus, facilitating its proliferation inside the insect [11] [12]. The purpose of this revision is to present the advances about the enzymes which synthetize the entomopathogenic fungi in the infective process, the strategies that have been developed with the purpose of increasing its bioinsecticide action and the potentiality those enzymes have as control agents in insects and plant diseases.

\section{Cuticle}

Most of the insects present a segmented cylindrical structure. The tegument rigidity is caused by the three layers which constitute it: cuticle, epidermis and basal membrane [13]. The cuticle serves as a physical barrier against parasites and diseases; it is a structure formed by crystalline chitin nanofibers inside a proteins, polyphenols and lipids matrix [14]. Its main component is chitin, a polysaccharide that is similar to cellulose. Monosaccharide units are bounded by $\beta-1,4$ bonds forming a linear molecule. The chains are arranged in anti-parallel mode and these are combined in a highly crystalline structure, where glucosamine molecules are bounded by hydrogen bonds, offering stiffness and chemical stability. Chitin nanofibers are approximately of 3 nm-diameter, and each one contains 19 molecular chains of near $0.3 \mu \mathrm{m}$ [15].

\section{Lipases}

The epicuticle, the external layer of the insect's cuticle is waterproof and acts as the first barrier against microbial attack. It is formed by heterogeneous mix of lipids, long-chain alkenes, esters and fatty acids. The importance of lipases in order to hydrolyze the ester bounds of lipoproteins, fats and waxes at the interior of the insect integument is well known [16]. They significantly contribute to the cuticle penetration and initial nutrients release. Once the epicuticle breaks down, the fungus produces great quantities of protease (Pr1) which degrade the proteinaceous material that is found in the procuticle. The importance of lipases in the tegument penetration and 
breaking down process has already been demonstrated [17]. A defense mechanism in the insect has also been identified. This consists in the ebelactone B secretion, a compound which inhibits the lypolytic activity, impeding the infection by the entomopathogenic fungi. Another function of lipases is that they improve the adhesion of the spores to the epicuticle, with the aim of initiating the fatty acids and alkenes degradation in the cuticle waxy surface. The conidial germination of the Nomuraea rileyi MJ fungus is significantly improved when it is combined with $81.3 \mathrm{kDa}$ lipase produced $N$. rileyi; it increases the Spodoptera litura larvae mortality, opening the possibility of streamlining the fungal infection process [18].

Recently, cytochrome P450 monooxygenase (CYP52) has been identified. This is important for the alkenes and insects epicuticle breaking down [19]. In B. bassiana, the gene encodes the lipase activity is Bbcyp52x1, corresponding to an enzymatic complex known as CYP52X1. This is a new P450 cytochrome subfamily which is involved in the hydrocarbons degradation. This enzyme shows certain activity $\omega$ hydroxylase capable of adding terminal hydroxyl groups in fatty acids and epoxides. [20]. In other lipases, the $\beta$-oxidation is implied followed by a transformation mediated by the peroxisome, with the purpose of obtaining the corresponding acyl-CoA [5] [21]. CYP52 fungal enzymes are versatile; the isoforms present different activities and specificities in relation to the kind of alkanes and/or fatty acids [22], offering great advantage to the entomopathogenic fungi to be simultaneously used as nutrients. The Bbcyp52x1 gene cluster of $B$. bassiana perform an important role in the epicuticle degradation, during the initial stages of the infection. Nonetheless, its action is no longer necessary whenever the cuticle breaks. For this reason, the lipidic substrates breaking down by the entomopathogenic fungi is the first step in the pathogenic process and at the same time, the cuticle penetration is performed [20]. In M. robertsii, the MrCYP52 gene from a cytochrome P450 subfamily has been identified. Differently from other entomopathogenic fungi, these do not present fatty acids $\Omega$-hydroxylation activity and alkanes are mainly oxide by the terminal methyl group; the promoter region contains CREA sites, indicating that it is regulated by catabolite repression [23].

\section{Proteases}

Some of the main characteristics of entomopathogenic fungi are their pathogenicity and virulence. Pathogenicity can be defined as the microorganism ability to cause disease meanwhile virulence is defined as the degree of pathogenicity that an organism uses in order to kill its host in controlled conditions. These characteristics are related to the proteases production; enzymes that are considered as the most important within the infective process [1]. When the epicuticle breaks down by the lipases, the fungus produces great quantities of Pr1 protease, which degrades the proteinaceous material. The solubilized proteins are degraded by amino peptidases and exopeptidases until amino acids, serving as nutrients for entomopathogenic fungi [24]. The most studied proteolytic enzymes most studied are the subtilisin-like serine-protease Pr1 and trypsin-like protease Pr2; the Pr1 protein gene corresponds to eleven isoforms that have been identified and cloned, besides a metalloprotease [25]. The molecular structure of subtilisin-like protease $\operatorname{Pr} 1$ is constituted by five cysteines forming two disulfide bridges, meanwhile the remaining cysteine is found near the catalytic triad formed of Asp39, His69 and Ser224 [26]. The activities of Pr1 and Pr2 have been determined in B. bassiana, M. anisopliae, Lecanicillium lecanni (Zimmerman) Viegas, Nomuraea rileyi (Farlow) Samson and Metarhizium flavoviride (Gams and Roszypal) [27]. These proteases are secreted during the first cuticle degradation stage and they are subject to a signal transduction mechanism with the activation of the protein kinase A (PKA) mediated by AMPc [28]. It has been demonstrated that, protease Pr1 is the key extracellular involved in the cuticle penetration and that, without this enzyme the infective process cannot be achieved [1] [29]. Besides, protease Pr1 is a virulence indicator for the entomopathogenic fungi [30]. Recently, new strategies have been employed in order to improve the entomopathogenic fungi virulence through genetic engineering with the construction of protease recombinants. For instance, $M$. anisopliae was transformed with the introduction of gene aaIT, which encodes a neurotoxin of the Androctonus australis scorpion, regulated by the gene $m c l 1$ promoter, solely expressed in the hemolymph [31]. Then, $B$. bassiana was genetically modified through the co-transformation of aaIT gene of A. australis and $\operatorname{pr} 1 \mathrm{~A}$ gene of the M. anisopliae protease. Nevertheless, there was no synergic effect was observed because as protease Pr1 used to degradation the AAIT protein [32]. For this reason, it was necessary evaluating the interaction between the two kinds of proteins and the stage where they must express. This means, Pr1A at the beginning of the infection and AAIT in the hemolymph. Due to the fact that protease Pr1 synergically acts with chitinases in the cuticle degradation, a fused gene was constructed presenting protease and chitinase activities. A co-transformation was made 
with the cdep1 gene encodes a Pr1A homolog and the Bbchit1 gene in B. bassiana, showing an evident time reduction in relation to the insect's death and with non protein break down [33]. Another case was the employment of cDNA of the protease gene CDEP, isolated from B. bassiana and fused with the cry $1 A c$ gen of Bacillus thuringiensis, under the control of the native promoter of the fungus, improving its insecticide activity over the Helicoverpa armigera larvae [34]. Of late, it has been classified, cloned and expressed in Escherichia coli; a Pr1 protease of $38 \mathrm{kDa}$ that presents high homology with serine protease (subtilisin type) produced by Lecanicillium (Verticillium) lecanii presenting an antifungal activity against different phytopathogenic fungi. This fact opens the possibility of using the entomopathogenic fungi in order to control plants diseases [35].

\section{Evaluative Features of Proteases in Entomopathogenic Fungi}

The pathogen-host (entomopathogenic fungi and insects) relation is in constant evolution. On the other hand, insects develop different strategies, with the purpose of defending themselves from pathogens [36], fungi have showed adaptations which allow them to overcome the inmune system defenses, successively completing the infective process [8]. In the last years, new data has been revealed about the genes evolution. For instance, that they are responsible of the host resistance or pathogen virulence. Most fungal genes that codify hydrolytic enzymes appertain to genes families (common origin) which codify products that present similar functions, specializing in several ecological niches [37].

Theoretically, entomopathogenic fungi double its genes after replication; a copy of the gene keeps the original function, meanwhile the other copy should present a modification in relation to amino acids, provoking a functional divergence. These adaptations are important for its evolution and persistence within the ecosystem, where the pathogen-host interaction takes place [38]. In a study where the diversity of subtilisin in M. anisopliae was classified it was found that this fungus is capable of infecting a great range of hosts, as it expresses 11 subtilisin during its growth in the insect cuticle. This is the highest number of subtilisin registered in any fungus, assuring the cuticle degradation in different orders of insects as well as its nutrition [39].

M. anisopliae presents great versatility as they are expressed in 32 genes from trypsin family; almost the double than Metarhizium acridum, and from 6 - 10 times more in comparison to other genus. Besides, the entomopathogenic fungi presented another evolutionary adaptation: the presence of chymotrypsin (MAA_07484) that might be acquired from bacteria through horizontal gene transfer [40].

The analysis of three entomopathogenic fungi genomes demonstrated that B. bassiana and Cordyceps militaris are strictly related. They have independently evolved from the Metarhizium spp. lineage. Neverthelees, in the case of genes, the proteases and chitinases expression necessary for pathogenesis reflects a convergent evolution in these three types of entomopathogenic fungi [41]. Lecanicillium spp. presents different isoforms of Pr1 protease and these isoforms differ in the substrate specificity and regulation, allowing the fungus to overcome the barrier that is founded in the insect cuticle during the penetration process [42]. As a result, the evolution of subtilisin in M. anisopliae offers a relatively high number of isoforms, whenever it acts as an entomopathogenic agent and in few isoforms during its life as saprophyte. The $11 \mathrm{M}$. anisopliae subtilisin are classified in four groups: class I corresponds to bacterial-type subtilisin Pr1C, meanwhile the other three groups are proteinase $\mathrm{K}$ class II subdivided into: extracellular subfamily 1 (Pr1A, Pr1B, Pr1G, Pr1I and Pr1K), extracellular subfamily 2 (Pr1D, Pr1E, Pr1F and Pr1J) and endocellular subtilisin (Pr1H). The phylogenetic analysis of other genus homologue sequences revealed that, proteinase K subdivision corresponds to the main fungi lineages [39]. The diversity isoforms allows the entomopathogenic fungi to infect different orders of insects. Through these adaptations, they persist in diverse agro-ecological niches, regulating populations of insects which present high incidence levels, as they control secondary pest (Figure 1).

\section{Chitinases}

Chitin is a $\beta-1,4 \mathrm{~N}$-acetyl glucosamine polymer; it is one of the most abundant polymer in nature after cellulose [43] as it is the main structural component of the fungi cellular walls and the invertebrates exoskeleton [44]. Chitinases hydrolyzes the $\beta-1,4$ bonds of chitin polymer producing a predominat $\mathrm{N}, \mathrm{N}$ '-diacetilchitobiose. This is break down by the chitobiose to $\mathrm{N}$-acetyl glucosamine (GlcNAc) monomer. Chitinases are widely distributed in plants, bacteria, fungi, insects and vertebrates [45]. They synergically act with proteases in order to degrade the insect's cuticle [46] and are associated to the different stages of entomopathogenic fungi. For instance: germination, hyphal growth, morphogenesis, nutrition and defense against competitors [47]. The filamentous fungi 


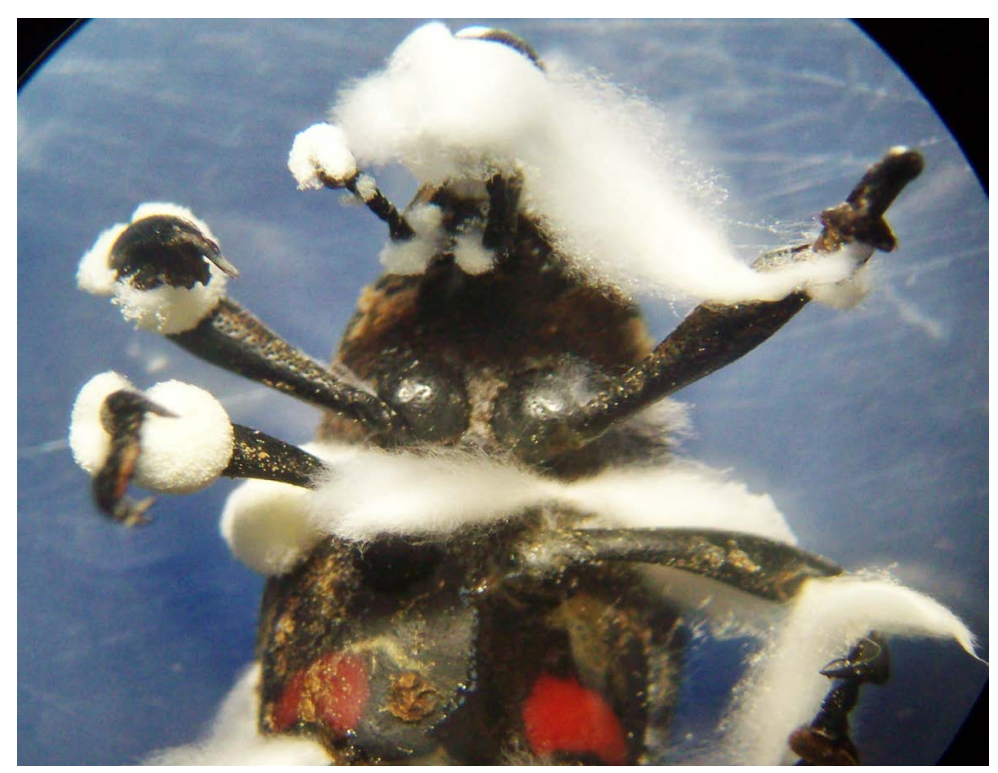

Figure 1. Infection by conidia from $B$. bassiana produced by solid-state fermentation on the cactus weevil Metamasius spinolae (Personal communication).

genome contains between 10 and 25 chitinases for different physiologic functions including: a) chitin degradation present in the fungi cellular walls or in the arthropods exoskeletons of arthropods used as nutrients source; b) cellular wall remodeling during the hyphae growth, branching, hyphae fusion, autolysis and competence; c) defense against other fungi located in the same ecological niche [12] [47].

Chitinases are classified into GH families 18 and 19 [48] [49]. GH Families 18 and 19 present no difference in its three-dimensional structures and correspond to chitinases classes III and V produced by bacteria, fungi, virus, animals and plants [50]. On the other hand, GH family 19 (classes I, II and IV) only refer to plants chitinases [51]. In accordance to its cut patterns, these enzymes might be classified as endochitinases which randomly break down chitin at any point within the polymer and exochitinases, releasing chitobiose from the non reductive extreme of the chain [46]. Chitinases have been recognized as powerful biological control agents due to its proved antifungal activity in Fusarium equiseti and as bioinsecticides in the diamond-back moth (Plutella xylostella) reducing the time of death [52]. The antagonist activity of Lecanicillium lecanii against the phytopathogenic fungus Oidium sp. has also been demostrated [53]. The first molecular characterization of a chitinase was for the chit1 gene in M. anisopliae [54], CHIT1 protein present a molecular weight of $42 \mathrm{kDa}$ and it is homologue to the Aspergillus album and Trichoderma harzianum chitinases. Moreover, [55] characterized the chi2 gene of M. anisopliae which codifies for a $42 \mathrm{kDa}$ chitinase regulated by catabolic repression. It is important to outline that it presents the same regulating mechanism that proteases (signal transduction) [28]. An analysis of the chit2 gene expression profile indicated the presence of two different transcribes giving evidence of an alternative RNA splicing, capable of showing the synthesis of two different proteins displaying different biological activities [56]. CHIT 30 chitinase of chi3 gene of M. anisopliae was expressed during the Rhipicephalus (Boophilus) microplus tick infection [57]; it is a specialized enzyme with exochitinase and endochitinase activity, involved in the heat stress adaptation [58]. As with protease Pr1, the expression of chitinases has been improved through genetic engineering. The first one was the chit1 gene of M. anisopliae sf. acridum overexpression. Nonetheless, there was no increase in the virulence against Manduca sexta [59]. The fact remains that, when a constitutive promoter was used for the chi2 gene of $M$. anisopliae overexpression, the time to death was reduced, even when alterations in the spores, hyphae and appressorium were detected [7]. Two chitinases of chit1 and chit2 genes were isolated and characterized from L. lecanii [45]. The chi1 gene codifies a protein of $40.9 \mathrm{kDa}$ with two functional domains: 1) catalytic domain, in the extreme $\mathrm{N}$-terminal and 2) chitin binding domain (ChBD) in the extreme C-terminal. This gene is homologue with Hypocrea lixii AAT37496, Coniothyrium minitans and Aspergillus fumigatus chitinases. The chit2 gene presents the same catalytic domain and ChBD sites and it is homologue to Aphanocladium album, Verticillium fungicola and B. bassiana chitinases. Bbchit1 gene 
of B. bassiana was also characterized; the protein presents a molecular weight of $33 \mathrm{kDa}$ and it is homologue to T. harzianum and Streptomyces avermitilis MA-4680 chitinases [60]. Nevertheless, it is not similar to other entomopathogenic fungi chitinases, indicating that there is a great variability of chitinases produced by these fungi. Besides, Bbchit1 gene contains two binding sites ChBD and its chitinolytic activity was increased through a directed evolution process by the construction of a series of variants, from which SHU-1 and SHU-2 presented the greatest enzymatic activity as result of the amino acids mutations outside of catalytic and substrate binding regions [61]. The $B$. bassiana virulence improved with a Bbchit1 gene recombinant with the chitin binding domain (ChBD) of silkworm mouth Bombyx mori, under the regulation of the fungus constitutive promoter, overexpressing the chitinase and reducing the time to death of infected insect [62]. Afterwards, the B. mori CHBD fragment was recombined with the $C D E P-1$ gene of $B$. bassiana serine protease, obtaining a hybrid protein which increased the binding ability of protease to the insect cuticle chitin, increasing its pathogenicity over the Myzus persicae larvae due to the proteic components solubilization that takes place in the insect cuticle [63].

\section{Chitinases: Phylogenetics Classifications into Three Subgroups}

A phylogenetic analysis based on the genomic sequences showed that fungal chitinases can be classified into three subgroups [64]. Subgroups A and B (corresponding to classes V and III, respectively) are the ones that were previously identified as fungal chitinases, meanwhile subgroup $C$ includes a new group of chitinases presenting a high molecular weight 140 - $170 \mathrm{kDa}$, identified in filamentous fungi. Chitinases appertaining to subgroup A have only one catalytic domain, but not the ChBD binding domain; its molecular weight is of 40 - 50 $\mathrm{kDa}$ and they are present in all the fungi genomes. Enzymes appertaining to subgroup B present an extremely variable size and domain structure. They have a molecular weight that might be located between 30 - $90 \mathrm{kDa}$. These can be grouped in low molecular weight chitinases (30 - $45 \mathrm{kDa}$ ) containing ChBD, a feature which is not present in subgroup A, and high molecular weight chitinases ( $90 \mathrm{kDa}$ ). The number of enzymes (Subgroup B) is variable but still, they are present in different species of ascomycete fungi. For instance: Magnaporthe grisea (T.T. Hebert) M.E. Barr, Aspergillus nidulans (G. Winter), Aspergillus niger, Mycosphaerella fijiensis (Morelet), Mycosphaerella graminicola (Fuckel) J. Schröt and Coccidoides immitis (G.W. Stiles) and basidiomycete fungi as in Laccaria bicolor (Maire), Phanerochaete chrysosporium (Gilman and Abbott) Carmich, Postia placenta (Fr.) M.J. Larsen and Lombard. Subgroup C is a new group of chitinases discovered in Hypocrea atroviridis (Trichoderma atroviride) CHI18-10 [62]. This subgroup presents a molecular weight of 140 - $170 \mathrm{kDa}$, showing a special role in the chitin degradation [44]. Besides, B. bassiana expresses 20 chitinases divided into three subgroups: eight appertaining to subgroup A (without ChBD binding); four appertaining to subgroup B (one ChBD in the extreme $\mathrm{C}$ terminal) and eight appertaining to subgroup $\mathrm{C}$ having two ChBD binding sites [41].

\section{Enzymes and Its Potential Production as Bioinsecticide}

Enzymes which break down the insect cuticle are an important virulence factor for the entomopathogenic fungi. There is certain correlation between pathogenicity and enzymes production [65] that can be used in order to cause cuticular structure weakening or slimming. Besides, if these enzymes arrive to the larvae intestine they might cause important damage in the peritrophic membrane structure. The result will be that they will not be capable of feeding themselves causing death [66]. This fact has opened a new potentiality in relation to enzymes as biocontrol agents in insects and additionally, against some diseases in plants caused by phytopathogenic fungi [67]. The enzymes efficacy has been proved against cotton aphid (Aphis gossyppii Glover) meanwhile, the insecticide action is mainly caused by chitinases [68]. In the Plutella xylostella larvae, the enzymes application significantly affects its growth and metamorphosis [69] [70].

Due to this fact, the entomopathogenic fungi enzymes production systems must be established (Figure 2). The Solid State Fermentation (SSF) is an adequate technology which is employed in the bioprocess development, facilitating its production at great scale. SSF presents some other advantages as: volumetric productivity, high product stability, low contamination risks and low instrumentation costs [71]. As examples of these bioprocesses we can mention: cellulose production by Trichoderma reesei [72] and cellulose and xilanase production by Aspergillus fumigatus [73]. Talking about the entomopathogenic fungi enzymes production which hydrolizes the cuticle, it should be pointed out that, substrats as Sphenarium purpurascens cuticle [74] or shrimp shell have been used in order to take advantage of the shrimp industry waste [53] (Figure 3). In the same way, Trichoderma koningii sp. chitinases and chitosanases have been produced [75]. 


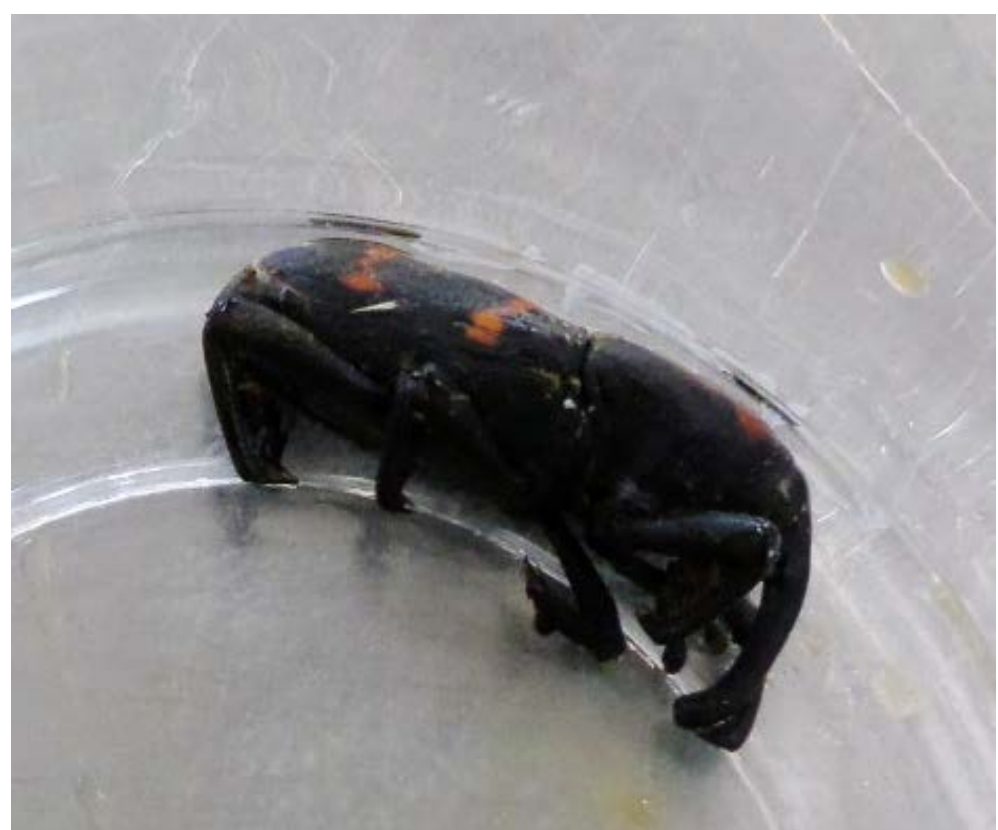

Figure 2. Treatment with enzymatic extract of B. bassiana produced by solidstate fermentation on the cactus weevil Metamasius spinolae (Personal communication).

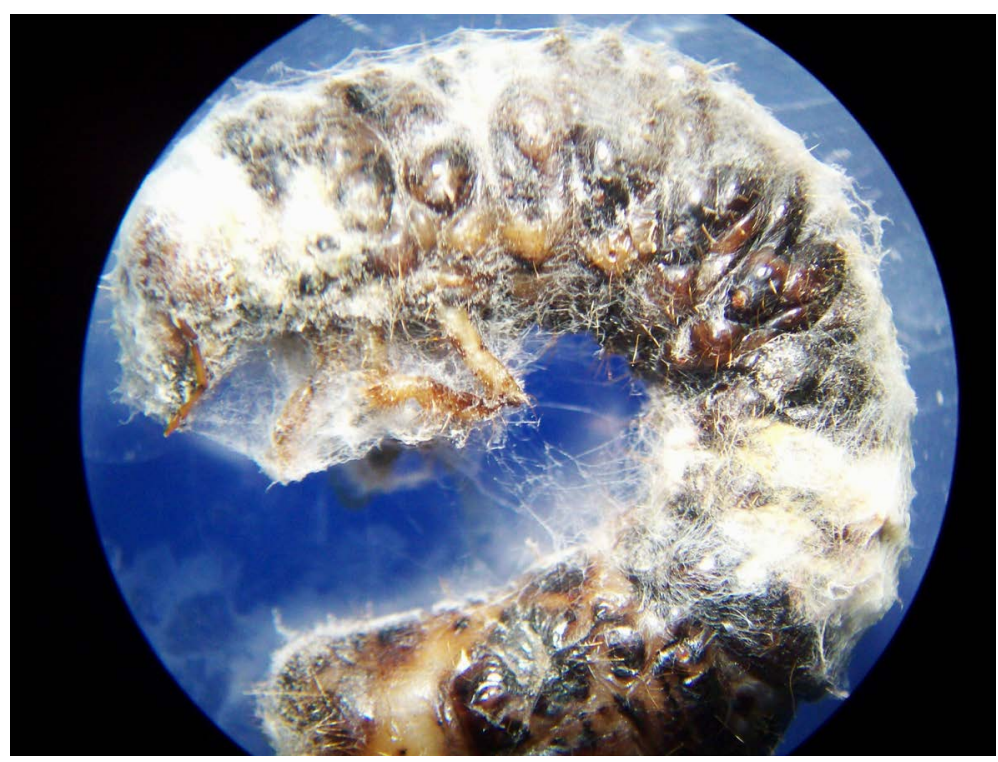

Figure 3. Treatment with conidia and enzymatic extract of B. bassiana produced by solid-state fermentation on the scarab beetle Cyclocephala lunulata (Personal communication).

Nevertheless, the SSF has mainly been used for producing entomopathogenic fungi conidia [76] [77] without considering all the system potentiality as biorefinery [78]. This would use discards with the intention of converting them into different kinds of products. For instance: conidia, enzymes, toxins, antibiotics and other secondary metabolites [79] presenting a wide range of applications in agriculture, medicine and the pharmaceutical industry.

\section{Conclusions}

The application of different molecular biology techniques have allowed to identify and understand the functions 
of lipases, proteases and chitinases in the entomopathogenic fungi infective process. Even though, there are still controversies about the action sequence and importance of several enzymes. As an example we can mention that the role of lipases during the infection process is not commonly recognized. The identification of cytochrome P450 subfamily involved in the hydrocarbon degradation confirms the importance of lipases at the beginning of the infective process. In relation to proteases, diversification of subtilisin-like Pr1 in entomopathogenic fungi allows having an infective response in different orders of insects, persisting in different ecological niches. Chitinases also presents multiple variability, facilitating the insect exoskeleton chitin degradation and showing fungicidal and insecticidal properties.

It has been possible to obtain recombinants (proteases and chitinases) through genetic engineering, reducing the time of death and making a more effective biological control for insect pest. Nevertheless, in the last few years, the role that these enzymes have in the infective process and its function as control agent is barely considered. This fact has opened a new research field in biotechnology with the intention of developing bioprocess that will be useful for a great scale production, along with strategies establishment and simultaneous application of conidia and enzymatic extracts, as well as the possibility of its usage as fungicide for controlling plants diseases [52]. Solid fermentation systems will produce conidia, enzymes and other metabolites for its application in agriculture, medicine and other industries.

\section{Acknowledgements}

Ll. C. Sánchez-Pérez was supported by a scholarship from CONACyT, México. We acknowledge Dr. Mihai Costea (Wilfrid Laurier University) for valuable comments on the manuscript.

\section{References}

[1] Mustafa, U. and Kaur, G. (2009) Extracellular Enzyme Production in Metarhizium anisopliae Isolates. Folia Microbiologica, 54, 499-504. http://dx.doi.org/10.1007/s12223-009-0071-0

[2] de Faria, M.R. and Wraight, S.P. (2007) Mycoinsecticides and Mycoacaricides: A Comprehensive List with Worldwide Coverage and International Classification of Formulation Types. Biological Control, 43, 237-256. http://dx.doi.org/10.1016/j.biocontrol.2007.08.001

[3] Charnley, A.K. and Collins, S.A. (2007) Entomopathogenic Fungi and Their Role in Pest Control. In: Kubicek, C.P. and Druzhinina, I.S., Eds., The Mycota IV: Environmental and Microbial Relationships, 2nd Edition, Springer-Verlag, Berlin, 159-187.

[4] Wösten, H.A.B. (2001) Hydrophobins: Multipurpose Proteins. Annual Review of Microbiology, 55, 625-646. http://dx.doi.org/10.1146/annurev.micro.55.1.625

[5] Pedrini, N., Crespo, R. and Juárez, M.P. (2007) Biochemistry of Insect Epicuticle Degradation by Entomopathogenic Fungi. Comparative Biochemistry and Physiology-Part C: Toxicology \& Pharmacology, 146, 124-137. http://dx.doi.org/10.1016/j.cbpc.2006.08.003

[6] Lubeck, I., Arrud, W., Souza, B.K., Stanisçuaski, F., Carlini, C. R., Schran, A., et al. (2008) Evaluation of Metarhizium anisopliae Strains as Potential Biocontrol Agents of the Tick Rhipicephalus (Boophilus) microplus and the Cotton Stainer Dysdercus peruvianus. Fungal Ecology, 1, 78-88. http://dx.doi.org/10.1016/j.funeco.2008.09.002

[7] Boldo, J.T., Junges, A., Amaral, K.B., Staats, C.C., Vainstein, M.H. and Schrank, A. (2009) Endochitinase CHI2 of the Biocontrol Fungus Metarhizium anisopliae Affects Its Virulence toward the Cotton Stainer Bug Dysdercus Peruvians. Current Genetics, 55, 551-560. http://dx.doi.org/10.1007/s00294-009-0267-5

[8] Wang, C.S. and St. Leger, R.J. (2006) A Collagenous Protective Coat Enables Metarhizium anisopliae to Evade Insect Immune Responses. Proceedings of the National Academy Sciences USA, 103, 6647-6652. http://dx.doi.org/10.1073/pnas.0601951103

[9] Arboleda-Valencia, J.W., Gaitán-Bustamante, A.L., Valencia-Jiménez, A. and Grossi-de-Sá, M.F. (2011) Cytotoxic Activity of Fungal Metabolites from the Pathogenic Fungus Beauveria bassiana: An Intraspecific Evaluation of Beauvericin Production. Current Microbiology, 63, 306-312. http://dx.doi.org/10.1007/s00284-011-9977-2

[10] Téllez, J.A. Cruz, M.G., Mercado, A. and Asaff, A.A. (2009) Mecanismos de Acción y Respuesta en la Relación de Hongos Entomopatógenos e Insectos. Revista Mexicana de Micología, 30, 73-80.

[11] Hasan, S., Ahmad, A., Purwar, A., Khan, N., Kundan, R. and Gupta, G. (2013) Production of Extracellular Enzymes in the Entomopathogenic Fungus Verticillium lecanii. Bioinformation, 9, 238-242. http://dx.doi.org/10.6026/97320630009238

[12] Yang, J., Tian, B., Liang, L. and Zhang, K.Q. (2007) Extracellular Enzymes and the Pathogenesis of Nematophagous 
Fungi. Applied Microbiology and Biotechnology, 75, 21-31. http://dx.doi.org/10.1007/s00253-007-0881-4

[13] Richards, O.W. and Davies, R.G. (1978) Imm's Outline of Entomology. 6th Edition, Chapman \& Hall Ltd., London.

[14] Vincent, F. and Wegst, G. (2004) Design and Mechanical Property of Insect Cuticle. Arthropod Structure Development, 33, 187-199. http://dx.doi.org/10.1016/j.asd.2004.05.006

[15] Vincent, J.F.V. (2002) Arthropod Cuticle: A Natural Composite Shell System. Composites Part A: Applied Science and Manufacturing, 33, 1311-1315. http://dx.doi.org/10.1016/S1359-835X(02)00167-7

[16] Ali, S., Huang, Z. and Ren, S.X. (2009) Production and Extraction of Extracellular Lipase from the Entomopathogenic Fungus Isaria fumosoroseus (Cordycipitaceae:Hypocreales). Biocontrol Sciences Technology, 19, 81-89. http://dx.doi.org/10.1080/09583150802588524

[17] da Silva, W.O.B., Santi, L., Scharank, A. and Vainstein, M.H. (2010) Metarhizium anisopliae Lipolytic Activity Plays a Pivotal Role in Rhipicepthalus (Boophilus) microplus Infection. Fungal Biology, 144, 10-15. http://dx.doi.org/10.1016/j.mycres.2009.08.003

[18] Supakdamrongkul, P., Bhumiratana, A. and Wiwat, C. (2010) Characterization of an Extracellular Lipase from the Biocontrol Fungus, Nomuraea rileyi MJ, and Its Toxicity toward Spodoptera litura. Journal of Invertebrate Pathology, 105, 228-235.

[19] Pedrini, N., Zhang, S., Juárez, M.P. and Keyhani, N.O. (2010) Molecular Characterization and Expression Analysis of a Suite of Cytochrome P450 Enzymes Implicated in Insect Hydrocarbon Degradation in the Entomopathogenic Fungus Beauveria bassiana. Microbiology, 156, 2549-2557. http://dx.doi.org/10.1099/mic.0.039735-0

[20] Zhang, S., Wideman, E., Bernard, G., Lesot, A., Pinot, E., Pedrini, N., et al. (2012) CYP52X1, Representing New Cytochrome P450 Subfamily, Displays Fatty Acid Hydroxylase Activity and Contributes to Virulence and Growth on Insect Cuticular Substrates in Entomopathogenic Fungus Beauveria bassiana. Journal of Biological Chemistry, 28, 13477-13486. http://dx.doi.org/10.1074/jbc.M111.338947

[21] Pedrini, N., Juárez M.P., Crespo, R. and de Alaniz, M.J.T. (2006) Clues on the Role of Beauveria bassiana Catalases in Alkane Degradation Events. Mycologia, 98, 528-534. http://dx.doi.org/10.3852/mycologia.98.4.528

[22] Van Bogaert, I.N., Groeneboer, S., Saerens, K. and Soetaert, W. (2011) The Role of Cytochrome P450 Monooxygenases in Microbial Fatty Acid Metabolism. FEBS Journal, 278, 206-221. http://dx.doi.org/10.1111/j.1742-4658.2010.07949.x

[23] Lin, L., Fang, W., Liao, X., Wang, F., Wei, D. and St. Leger, R.J. (2011) The MrCYP52 Cytochrome P450 Monooxygenase Gene of Metarhizium robertsii Is Important for Utilizing Insect Epicuticular Hydrocarbons. PLoS ONE, 6, e28984. http://dx.doi.org/10.1371/journal.pone.0028984

[24] Wang, C., Typas, M.A. and Butt, T.M. (2002) Detection and Characterization of Pr1 Virulent Gene Deficiencies in the Insect Pathogenic Fungus Metarhizium anisopliae. FEMS Microbiology Letters, 213, 251-255. http://dx.doi.org/10.1111/j.1574-6968.2002.tb11314.x

[25] St. Leger, R.J., Bidochka, M.J. and Roberts, D.W. (1994) Isoforms of the Cuticle-Degrading Pr1 Proteinase and Production of a Metalloproteinase by Metarhizium anisopliae. Archives of Biochemistry Biophysics, 313, 1-7. http://dx.doi.org/10.1006/abbi.1994.1350

[26] Liu, S.Q., Meng, Z.H., Yang, J.K., Fu, Y.K. and Zhang, K.Q. (2007) Characterizing Structural Features of CuticleDegrading Proteases form Fungi by Molecular Modeling. BMC Structural Biology, 7, 33. http://dx.doi.org/10.1186/1472-6807-7-33

[27] Bidochka, M.J. and Meltzer, M.J. (2000) Genetic Polymorphisms in Three Subtilisin-Like Protease Isoforms (Pr1A, Pr1B, and Pr1C) from Metarhizium Strains. Canadian Journal Microbiology, 46, 1138-1144. http://dx.doi.org/10.1139/w00-112

[28] Fang, W., Pava-Ripoli, M., Wang, S. and St. Leger, R.J. (2009) Protein Kinase A Regulates Production of Virulence Determinants by the Entomopathogenic Fungus, Metarhizium anisopliae. Fungal Genetic Biology, 46, 277-285. http://dx.doi.org/10.1016/j.fgb.2008.12.001

[29] Sun, M.H. and Liu, X.Z. (2006) Carbon Requirements of Some Entomopathogenic and Mycoparasitic Hyphomycetes as Fungal Biocontrol Agents. Mycopathology, 161, 295-305. http://dx.doi.org/10.1007/s11046-006-0249-9

[30] Castellanos-Moguel, J., González-Barajas, M., Mier, T., Reyes Montes, M.R., Aranda, E. and Toriello, C. (2007) Virulence Testing and Extracellular Subtilisin-Like (Pr1) and Tripsina-Like (Pr2) Activity during Propagule Production of Paecilomyces fumosoroseus Isolates from Whiteflies (Homoptera: Aeyrodidae). Revista Iberoamericana de Micología, 24, 62-68.

[31] Wang, C. and St. Leger, R.J. (2007) A Scorpion Neurotoxin Increases the Potency of a Fungal Insecticide. Nature Biotechnology, 25, 1455-1456. http://dx.doi.org/10.1038/nbt1357

[32] Lu, D.M., Pava-Ripoli, M., Li, Z. and Wang, C. (2008) Insecticidal Evaluation of Beauveria bassiana Engineered to 
Express a Scorpion Neurotoxin and a Cuticle Degrading Protease. Applied Microbiology Biotechnology, 81, 515-522. http://dx.doi.org/10.1007/s00253-008-1695-8

[33] Fang, W., Feng, J., Fan, Y., Zhang, Y., Bidochka, M.J., St. Leger, R.J. and Pei, Y. (2009) Expressing a Fusion Protein with Protease and Chitinase Activities Increases the Virulence of the Insect Pathogen Beauveria bassiana. Journal of Invertebrate Pathology, 102, 155-159. http://dx.doi.org/10.1016/j.jip.2009.07.013

[34] Xia, L., Zeng, Z., Ding, X. and Huang, F. (2009) The Expression of a Recombinant Cry1Ac Gene with Subtilisin-Like Protease CDEP2 Gene in Acrystalliferous Bacillus thuringiensis by Red/ET Homologous Recombination. Current Microbiology, 59, 386-392. http://dx.doi.org/10.1007/s00284-009-9449-0

[35] Yu, G., Liu, J., Xie, L., Wang, X., Zhang, S. and Pan, H. (2012) Characterization, Cloning and Heterologous Expression of a Subtilisin-Like Serine Protease Gene VlPr1 from Verticillium lecanii. Journal of Microbiology, 50, 939-946. http://dx.doi.org/10.1007/s12275-012-2199-x

[36] Dubovskiy, I.M., Whitten, M.M.A., Yaroslavtseva, O.N., Greig, C., Kryukov, V.Y., et al. (2013) Can Insects Develop Resistance to Insect Pathogenic Fungi? PLoS ONE, 8, e60248. http://dx.doi.org/10.1371/journal.pone.0060248

[37] Sprockett, D.D., Piontkivska, H. and Blackwood, C.B. (2011) Evolutionary Analysis of Glycosil Hydrolase Family 28 (GH28) Suggest Lineage-Specific Expansions in Necrotrophic Fungal Pathogens. Gene, 479, 29-36. http://dx.doi.org/10.1016/j.gene.2011.02.009

[38] Graur, H. and Li, W.H. (2000) Fundamentals of Molecular Evolution. 2nd Edition, Sinauer Associates, Sunderland.

[39] Bagga, S., Hu, G., Screen, S.E. and St. Leger, J.R. (2004) Reconstructing the Diversification of Subtilisins in the Pathogenic Fungus Metarhizium anisopliae. Gene, 324, 159-169. http://dx.doi.org/10.1016/j.gene.2003.09.031

[40] Xu, Y., Orozco, R., Wijeratne, E.M.K., Gunatilaka, A.A.L., Stock, S.P. and Molnár, I. (2008) Biosynthesis of the Cyclooligomer Depsipeptide Beauvericin, a Virulence Factor of the Entomopathogenic Fungus Beauveria bassiana. Chemistry \& Biology, 15, 898-907. http://dx.doi.org/10.1016/j.chembiol.2008.07.011

[41] Xiao, G., Ying, S.H., Zheng, P., Wang, Z.L., Zhang, S., Xie, X.Q., et al. (2012) Genomic Perspectives on the Evolution of Fungal Entomopathogenicity in Beauveria bassiana. Scientific Reports, 2, Article No. 483. http://dx.doi.org/10.1038/srep00483

[42] Bye, N.J. and Charnley, A.K. (2008) Regulation of Cuticle-Degrading Subtilisin Proteases from the Entomopathogenic Fungi, Lecanicillium spp: Implications for Host Specificity. Archives of Microbiology, 189, 81-92. http://dx.doi.org/10.1007/s00203-007-0296-8

[43] Tharanathan, R.N. and Kittur, F.S. (2003) Chitin-The Undisputed Biomolecule of Great Potential. Critical Reviews in Food Science and Nutrition, 43, 61-87. http://dx.doi.org/10.1080/10408690390826455

[44] Seidl, V. (2008) Chitinases of Filamentous Fungi: A Large Group of Diverse Proteins with Multiple Physiological Functions. Fungal Biology Reviews, 22, 36-42. http://dx.doi.org/10.1016/j.fbr.2008.03.002

[45] Lu, Z.X., Laroche, A. and Huang H.C. (2005) Isolation and Characterization of Chitinases from Verticillium lecanii. Canadian Journal Microbiology, 51, 1045-1055. http://dx.doi.org/10.1139/w05-088

[46] St. Leger, R.J., Cooper, R.M. and Charnley, A.K. (1991) Characterization of Chitinase and Chitobiose Produced by the Entomopathogenic Fungus Metarhizium anisopliae. Journal of Invertebrate Pathology, 58, 415-426. http://dx.doi.org/10.1016/0022-2011(91)90188-V

[47] Adams, D.J. (2004) Fungal Cell Wall Chitinases and Glucanases. Microbiology, 150, 2029-2035. http://dx.doi.org/10.1099/mic.0.26980-0

[48] Henrissat, B. and Bairoch, A. (1993) New Families in the Classification of Glycosyl Hydrolases Based on Aminoacid Sequence Similarities. Biochemistry, 293, 781-788.

[49] Li, D.C. (2006) Review of Fungal Chitinases. Mycopathologia, 161, 345-360. http://dx.doi.org/10.1007/s11046-006-0024-y

[50] Kezuka, Y., Ohishi, M., Itoh, Y., Watanabe, J., Mitsutomi, M., Watanebe, T., et al. (2006) Structural Studies of a TwoDomain Chitinase from Streptomyces griseus HUT6037. Journal of Molecular Biology, 358, 472-484. http://dx.doi.org/10.1016/j.jmb.2006.02.013

[51] Sahai, A.S. and Manocha, M.S. (1993) Chitinases of Fungi and Plants: Their Involvement in Morphogenesis and HostParasite Interaction. FEMS Microbiology Reviews, 11, 317-338. http://dx.doi.org/10.1111/j.1574-6976.1993.tb00004.x

[52] Prasanna, L., Eijsink, V.G.H., Meadow, R. and Gåseidnes, S. (2013) A Novel Strain of Brevibacillus laterosporus Produces Chitinases That Contribute to Its Biocontrol Potential. Applied Microbiology Biotechnology, 97, 1601-1611. http://dx.doi.org/10.1007/s00253-012-4019-y

[53] Barranco-Florido, E., Bustamante-Camilo, L., Mayorga-Reyes, L., González-Cervantes, R., Martínez-Cruz, P. and Azaola, A. (2009) $\beta$-N-Acetylglucosamidase Production by Lecanicillium lecanii ATCC 26854 by Solid-State Fermentation Utilizing Shrimp Shell. Interciencia, 34, 356-360. 
[54] Bogo, M.R., Rota, C.A., Rota, H., Pinto Jr, H., Ocampos, M., Correa, C.T., et al. (1998) A Chitinase Encoding Gene (chit1 Gene) from the Entomopathogen Metarhizium anisopliae: Isolation and Characterization of Genomic and FullLength cDNA. Current Microbiology, 37, 221-225. http://dx.doi.org/10.1007/s002849900368

[55] Baratto, C.M., Dutra, V., Tomazzoni, J., Barbosa, L., Henning, M. and Schrank, A. (2006) Isolation, Characterization, and Transcriptional Analysis of the Chitinase chit2 Gene (DQ011663) from the Biocontrol Fungus Metarhizium anisopliae var. anisopliae. Current Microbiology, 53, 217-221. http://dx.doi.org/10.1007/s00284-006-0078-6

[56] Boldo, J.T., Amaral, K.B., Junges, A., Pinto, P.M., Staats, C.C., Vainstein, M.H. et al. (2010) Evidence of Alternative Splicing of the chit2 Chitinase Gene from Metarhizium anisopliae. Gene, 462, 1-7. http://dx.doi.org/10.1016/j.gene.2010.04.005

[57] da Silva, M.V., Santi, L., Staats, C.C., da Costa, A.M., Colodel, E.M., Driemeier, D., et al. (2005) Cuticle Induced Endo/Exoacting Chitinase CHIT30 from Metarhizium anisopliae Is Encoded by an Ortholog of the chit3 Gene. Research in Microbiology, 156, 382-392. http://dx.doi.org/10.1016/j.resmic.2004.10.013

[58] Staats, C.C., Kmetzsch, L., Lubeck, I., Junges, A., Vainstein, M.H. and Schrank, A. (2013) Metarhizium anisopliae Chitinase CHIT30 Is Involved in Heat-Shock Stress and Contributes to Virulence against Dysdercus peruvians. Fungal Biology, 117, 137-144. http://dx.doi.org/10.1016/j.funbio.2012.12.006

[59] Screen, S., Hu, G. and St. Leger., R.J. (2002) Transformants of Metarhizium anisopliae sf. anisopliae Overexpressing Chitinase from Metarhizium anisopliae sf. acridum Show Early Induction of Native Chitinase but Are Not Altered in Pathogenicity to Manduca sexta. Journal of Invertebrate Pathology, 78, 260-266. http://dx.doi.org/10.1006/jipa.2001.5067

[60] Fang, W., Leng, B., Xiao, Y., Jin, K., Ma., J., Fan, Y., et al. (2005) Cloning of Beauveria bassiana Gene Bbchit1 and Its Application to Improve Fungal Strain Virulence. Applied and Environmental Microbiology, 71, 363-370.

[61] Fan, Y., Fang, W., Xiao, Y., Yang, X., Zhang, Y., Bidochka, M.J., et al. (2007) Directed Evolution for Increased Chitinase Activity. Applied Microbiology and Biotechnology, 76, 135-139. http://dx.doi.org/10.1007/s00253-007-0996-7

[62] Fan, Y., Fang, W., Guo, S., Pei, X., Zhang, Y., Xiao, Y., et al. (2007) Increased Insect Virulence in Beauveria bassiana Strains Overexpressing an Engineered Chitinase. Applied and Environmental Microbiology, 73, 295-302. http://dx.doi.org/10.1128/AEM.01974-06

[63] Fan, Y., Pei, X., Guo, S., Zhang, Y., Luo, Z., Liao, X., et al. (2010) Increased Virulence Using Engineered ProteaseChitin Binding Domain Hybrid Expressed in the Entomopathogenic Fungus Beauveria bassiana. Microbial Pathogenesis, 49, 376-380. http://dx.doi.org/10.1016/j.micpath.2010.06.013

[64] Seidl, V., Huemer, B., Seiboth, B. and Kubicek, C.P. (2005) A Complete Survey of Trichoderma Chitinases Reveals Three Distinct Subgroups of Family 18 Chitinases. FEBS Journal, 272, 5923-5939. http://dx.doi.org/10.1111/j.1742-4658.2005.04994.x

[65] Kaur, G. and Padmaja, V. (2009) Relationships among Activities of Extracellular Enzyme Production and Virulence against Helicoverpa armigera in Beauveria bassiana. Journal of Basic Microbiology, 49, 264-274. http://dx.doi.org/10.1002/jobm.200800156

[66] Binod, P., Sukumaran, R.K., Shirke, S.V., Rajpur, J.C. and Pandey, A. (2007) Evaluation of Fungal Cultures Filtrate Containing Chitinase as a Biocontrol Agent against Helicoverpa ormigera. Journal of Applied Microbiology, 103, 1845-1852. http://dx.doi.org/10.1111/j.1365-2672.2007.03428.x

[67] Ownley, B.H., Griffin, M.R., Klingeman, W.E., Gwinn, K.D., Moulton, J.K. and Pereira, R.M. (2008) Beauveria bassiana: Endophytic Colonization and Plant Disease Control. Journal of Invertebrate Pathology, 98, 267-270. http://dx.doi.org/10.1016/j.jip.2008.01.010

[68] Kim, J.S., Roh, J.Y., Choi, J.Y., Wang, Y., Shim, H.J. and Je, Y.H. (2010) Correlation of the Aphicidal Activity of Beauveria bassiana SFB-205 Supernatant with Enzymes. Fungal Biology, 114, 120-128. http://dx.doi.org/10.1016/j.mycres.2009.10.011

[69] Ali, S., Huang, Z. and Ren, S. (2010) Production of Cuticle Degrading Enzymes by Isaria fumosorosea and Their Evaluation as a Biocontrol Agent against Diamondback Moth. Journal of Pest Sciences, 83, 361-370. http://dx.doi.org/10.1007/s10340-010-0305-6

[70] Shoaib, F., Jin, F.L., Muhammad, N., Ren, S.X. and Mubshar, H. (2012) Toxicity of Proteins Secreted by Entomopathogenic Fungi against Plutella xylostella (Lepidoptera: Plutellidae). International Journal of Agriculture and Biology, 14, 291-295.

[71] Renge, V.C., Khedkar, S.V. and Nandurkar, N.R. (2012) Enzyme Synthesis by Fermentation Method: A Review. Scientific Reviews and Chemical Communications, 2, 585-590.

[72] Oberoi, H.S., Chavan, Y., Bansai, S. and Dhillon, G.S. (2010) Production of Cellulases through Solid State Fermentation Using Kinnow Pulp as a Major Substrate. Food and Bioprocess Technology, 3, 528-536. 
http://dx.doi.org/10.1007/s11947-008-0092-8

[73] Ang, S.K., Shaza, E.M., Adibah, Y., Suraini, A.A. and Madihah, M.S. (2013) Production of Cellulases and Xylanase by Aspergillus fumigatus SK1 Using Untreated Oil Palm Trunk through Solid State Fermentation. Process Biochemistry, 48, 1293-1302. http://dx.doi.org/10.1016/j.procbio.2013.06.019

[74] Barranco-Florido, J.E., Alatorre-Rosas, R., Gutiérrez-Rojas, M., Viniegra-González, G. and Saucedo-Castañeda, G. (2002) Criteria for the Selection of Strains of Entomopathogenic Fungi Verticillium lecanii for Solid State Cultivation. Enzyme and Microbial Technology, 30, 910-915. http://dx.doi.org/10.1016/S0141-0229(02)00032-7

[75] da Silva, L.C.A., Honorato, T.L., Franco, T.T. and Rodrigues, S. (2012) Optimization of Chitosanase Production by Trichoderma koningii sp. under Solid-State Fermentation. Food and Bioprocess Technology, 5, 1564-1572. http://dx.doi.org/10.1007/s11947-010-0479-1

[76] Kim, J.S., Kassa, A., Skinner, M., Hata, T. and Parker, B.L. (2011) Production of Thermotolerant Entomopathogenic Fungal Conidia on Millet Grain. Journal of Industrial Microbiology and Biotechnology, 38, 697-704. http://dx.doi.org/10.1007/s10295-010-0850-2

[77] Mascarin, G.M., Kobori, N.N., Quintela, E.D. and Delalibera Jr., I. (2013) The Virulence of Entomopathogenic fungi against Bemisia tabaci Biotype B (Hemiptera: Aleyrodidae) and Their Conidial Production Using Solid Substrate Fermentation. Biological Control, 66, 209-218.

[78] Erickson, B., Nelson, J.E. and Winters, P. (2012) Perspective on Opportunities in Industrial Biotechnology in Renewable Chemicals. Biotechnology Journal, 7, 176-185. http://dx.doi.org/10.1002/biot.201100069

[79] de Bekker, C., Smith, P.B., Patterson, A.D. and Hughes, D.P. (2013) Metabolomics Reveals the Heterogeneous Secretome of Two Entomopathogenic Fungi to ex Vivo Cultured Insect Tissues. PloS ONE, 8, e70609. http://dx.doi.org/10.1371/journal.pone.0070609 